OPEN ACCESS

Edited by:

Anne-Marie Baird,

St. James's Hospital, Ireland

Reviewed by:

Philippe Rondard,

Centre National de la Recherche

Scientifique (CNRS), France

Stefano Espinoza,

Istituto Italiano di Tecnologia, Italy

*Correspondence:

Terence E. Hébert

terence.hebert@mcgill.ca

Specialty section:

This article was submitted to

Molecular and Structural

Endocrinology,

a section of the journal

Frontiers in Endocrinology

Received: 21 November 2018

Accepted: 26 February 2019

Published: 18 March 2019

Citation:

Fillion $D$, Devost $D$, Sleno $R$, Inoue $A$ and Hébert TE (2019) Asymmetric Recruitment of $\beta$-Arrestin $1 / 2$ by the Angiotensin II Type I and Prostaglandin F2 $\alpha$ Receptor Dimer.

Front. Endocrinol. 10:162.

doi: 10.3389/fendo.2019.00162

\section{Asymmetric Recruitment of $\beta$-Arrestin1/2 by the Angiotensin II Type I and Prostaglandin F2 $\alpha$ Receptor Dimer}

\author{
Dany Fillion ${ }^{1}$, Dominic Devost ${ }^{1}$, Rory Sleno ${ }^{1}$, Asuka Inoue ${ }^{2,3}$ and Terence E. Hébert ${ }^{\text {* }}$ \\ ${ }^{1}$ Department of Pharmacology and Therapeutics, McGill University, Montréal, QC, Canada, ${ }^{2}$ Graduate School of \\ Pharmaceutical Sciences, Tohoku University, Sendai, Japan, ${ }^{3}$ Japan Science and Technology Agency, Precursory \\ Research for Embryonic Science and Technology, Kawaguchi, Japan
}

Initially identified as monomers, G protein-coupled receptors (GPCRs) can also form functional homo- and heterodimers that act as distinct signaling hubs for cellular signal integration. We previously found that the angiotensin II (Ang II) type 1 receptor (AT1R) and the prostaglandin F2 $\alpha$ (PGF2 $\alpha$ ) receptor (FP), both important in the control of smooth muscle contractility, form such a functional heterodimeric complex in HEK 293 and vascular smooth muscle cells. Here, we hypothesize that both Ang II- and PGF2 $\alpha$-induced activation of the AT1R/FP dimer, or the parent receptors alone, differentially regulate signaling by distinct patterns of $\beta$-arrestin recruitment. Using BRET-based biosensors, we assessed the recruitment kinetics of $\beta$-arrestin1/2 to the AT1R/FP dimer, or the parent receptors alone, when stimulated by either Ang II or PGF2 $\alpha$. Using cell lines with CRISPR/Cas9-mediated gene deletion, we also examined the role of $G$ proteins in such recruitment. We observed that Ang II induced a rapid, robust, and sustained recruitment of $\beta$-arrestin1/2 to AT1R and, to a lesser extent, the heterodimer, as expected, since AT1R is a strong recruiter of both $\beta$-arrestin subtypes. However, PGF2 $\alpha$ did not induce such recruitment to FP alone, although it did when the AT1R is present as a heterodimer. $\beta$-arrestins were likely recruited to the AT1R partner of the dimer. $G \alpha_{q}$, $\mathrm{G} \alpha_{11}, \mathrm{G} \alpha_{12}$, and $\mathrm{G} \alpha_{13}$ were all involved to some extent in PGF2 $\alpha$-induced $\beta$-arrestin1/2 recruitment to the dimer as their combined absence abrogated the response, and their separate re-expression was sufficient to partially restore it. Taken together, our data sheds light on a new mechanism whereby PGF2 $\alpha$ specifically recruits and signals through $\beta$-arrestin but only in the context of the AT1R/FP dimer, suggesting that this may be a new allosteric signaling entity.

\footnotetext{
Keywords: G protein-coupled receptor (GPCR), dimerization, allosteric regulation, arrestin, angiotensin, prostaglandin
}

\section{INTRODUCTION}

G protein-coupled receptors (GPCRs) have historically been studied and understood as functional monomers. Although well-established for class-C GPCRs $(1,2)$, an increasing body of evidence now supports that class-A GPCRs also form dimers $(3,4)$ and even higher-order oligomers; however, the exact physiological significance, and pharmacological importance of such complexes still remain 
elusive. Given that GPCRs are one of the most successfully exploited drug targets, the continuing emergence of dimers represent a promising opportunity not only to better understand GPCR biology and their roles in disease etiology, but also to reveal their full therapeutic potential as unique functional entities (5).

One untapped feature of GPCR dimers might be a potential ability to assemble according to cellular needs and to combine two separate, independent orthosteric binding sites-especially true for heterodimers-where one receptor protomer can potentially allosterically modulate the function of the other, and vice-versa. Further, GPCR dimers can also allow different intracellular signaling partners to selectively interact with only one of the two protomers or both, expanding the possibilities for the cell to adapt to different conditions. For example, a D2 dopamine receptor homodimer was found to be organized asymmetrically with respect to its $G$ protein partners such that occupation of the first protomer facilitated downstream cellular signaling through the second protomer, while occupation of the latter (or even its constitutive activity) modulated signaling allosterically without inducing a signal on its own (6). In the context of such a functional dimeric assembly, benefits usually attributed to allosteric modulators can be derived from an otherwise orthosteric site, offering novel avenues to fine-tune signaling efficacy, improve receptor subtype selectivity and tissue specificity as well as off target effects (7).

For most class-A GPCR dimers, the minimal signaling unit is thought to be composed of two receptors and one heterotrimeric $\mathrm{G}$ protein to form a pentameric structure $(3,4,6)$. Interestingly, monomeric GPCRs have recently been found to also form what is called a super-complex, or "megaplex," by simultaneously binding through its core region with $\mathrm{G}$ protein and through its phosphorylated C-terminal tail with $\beta$-arrestin (8); therefore, opening the possibility for GPCR dimers to form higher-order oligomeric complexes with both $G$ protein and $\beta$-arrestin. Indeed, $\beta$-arrestin has been demonstrated to adopt two distinct conformations when bound to an engineered $\beta_{2}$-adrenergic receptor ( $\left.\beta_{2} \mathrm{AR}\right)$ (9). $\beta$-arrestin adopts a more engaged "core" conformation in which it contacts extensively with the transmembrane domains, the intracellular loops along with the phosphorylated C-terminal tail of the receptor, and a more relaxed conformation ("core" conformation) in which it contacts with the receptor C-terminal tail only, allowing $\beta$ arrestin to more freely hang from the receptor and exposing the entire intracellular surface (9). Some crystal structures of GPCRs also appear to support the formation of "megaplex." An arrangement similar to the "core" conformation have been reported in a rhodopsin/visual arrestin crystal structure (10), while the $\beta_{2} \mathrm{AR} / \mathrm{Gs}$ protein crystal structure seems compatible with the "tail" conformation and the simultaneous presence of $\mathrm{G}$ protein and $\beta$-arrestin (11).

\footnotetext{
Abbreviations: GPCR, G protein-coupled receptor; Ang II, angiotensin; AT1R, angiotensin II type I receptor; PGF $2 \alpha$, prostaglandin $2 \alpha$; FP, prostaglandin $2 \alpha$ receptor; BRET, bioluminescence resonance energy transfer; FlAsH, fluorescein arsenical hairpin binder; RlucII, Renilla luciferase II.
}

A hurdle in investigating class-A GPCR dimerization has been the limited capacity to identify the respective function of the protomers within a dimer, that is which protomer binds the ligand and which protomer signals. This minimal functional unit is used to investigate the interplay between $\beta$-arrestin $1 / 2$ and multiple $G$ proteins at the larger intracellular interface of a GPCR dimer using a panel of BRET-based biosensors. We previously showed that AT1R and FP could be co-purified together using immunoprecipitation in HEK 293 cells and in vascular smooth muscle cells combined with photoaffinity labeling (12). We noted that FP antagonists resulted in inhibition of Ang IImediated contraction, an effect that cannot be mediated by second messenger-activated crosstalk via protein kinases, since these ligands did not activate such signaling events. Similar results were obtained when we pre-treated cells with an AT1R antagonist when measuring FP-mediated contraction (12).

We also engineered FlAsH tags and Renilla luciferase into both AT1R and FP and co-expressed them with their untagged counterparts (13). We again noted asymmetric transmission of conformational information between protomers. AT1R-induced conformational rearrangements in FP were dependent on both the presence of activatable $\mathrm{G} \alpha_{\mathrm{q}}$ as well as the possible involvement of phospholipase $C \beta$, a proximal $G \alpha_{\mathrm{q}}$-effector. Association of GPCRs, G proteins and effectors likely represent core units of signaling complex organization, which is reflected by mutual allosteric effects. We also showed that AT1R-driven conformational changes in FP were independent of the activation of PKC, a shared downstream receptor signaling pathway. Allosteric interactions occur in the plasma membrane, mediated through a shared $G$ protein in a heterodimer. The AT1R/FP heterodimer remained intact even in the absence of $G \alpha_{\mathrm{q}}$, thus they are not required for assembly of receptor heterodimers rather allosterically connecting the two receptors as part of signaling complexes. With respect to allosteric interactions in the AT1R/FP dimer, AT1R was able to modulate FP conformation but the converse was not true (at least with the biosensors we were using) (14). Further, the AT1R to FP conformational crosstalk in the heterodimer was biased toward $\mathrm{G \alpha}_{\mathrm{q} / 11}$ as a preferred heterodimer partner, as no conformational effects were observed when $G \alpha_{12 / 13}$ or $G \alpha_{i}$ function or levels were altered. Such a perceived coupling preference in the heterodimer might again be because our initial panels of conformational biosensors may have only been sensitive to the presence of particular $G$ proteins. Here, we extend this finding to $\beta$-arrestin to show how this scaffolding/adaptor protein can be symmetrically (e.g., cisactivation) and asymmetrically (e.g., trans-activation) regulated in response to Ang II and PGF2 $\alpha$, respectively.

\section{MATERIALS AND METHODS}

\section{Materials}

All cell culture media, reagents, and antibiotics were from Wisent Inc. (St-Bruno, Québec, Canada). All DNA primers for molecular cloning were custom-made by Integrated DNA Technologies Inc. (Coralville, IA, USA). All enzymes and other materials used for molecular cloning were from New England Biolabs Ltd. (Ipswich, MA, USA), except for the Pvu II and Taq I 
restriction enzymes that were both from Takara Bio Inc. (Noji Higashi, Kusatsu Shiga, Japan). Cell transfection reagent was from Invitrogen, Thermo Fisher Scientific Inc. (Waltham, MA, USA). All chemicals, including Ang II and the AT1R antagonists were from Sigma-Aldrich Inc. (St. Louis, MO, USA) unless otherwise specified. PGF2 $\alpha$ and cloprostenol were from Cayman Chemical Company (Ann Arbor, MI, USA). Coelenterazine h was from NanoLight Technologies (Pinetop, AZ, USA).

\section{CRISPR-Gene Deletion Lines}

As recently reported (14), the HEK $293 \Delta \mathrm{G} \alpha_{\mathrm{q} / 11 / 12 / 13}$ cell line wherein all the genes encoding for $G_{q}, G_{11}, G_{12}$, and $G_{13}$ proteins have been knocked out was generated by simultaneously targeting the GNA12 and the GNA13 genes of the previously established HEK $293 \Delta \mathrm{G} \alpha_{\mathrm{q} / 11}$ cells (15), using CRISPR/Cas9 as described previously (16).

\section{Molecular Cloning and Mutagenesis}

The following plasmids pcDNA3/SP-FLAG-hAT1R-WT (12), pcDNA3.1/SP-FLAG-hAT1R-RlucII (17), pcDNA3/SP-HA-hFPRlucII (18), $\beta$-arrestin 1-RlucII $(19,20), \beta$-arrestin 2-RlucII $(19,20)$ were used. A K44 dynamin mutant in pcDNA3 was a generous gift from Dr. Denis Dupré (Dalhousie University). The different pcDNA3.1 plasmids encoding $G \alpha_{q}, G \alpha_{11}$, $\mathrm{G} \alpha_{12}, \mathrm{G} \alpha_{13}$ were from UMR cDNA resource center (www. cdna.org; University of Missouri-Rolla, Rolla, MO, USA). The pcDNA3.1/SP-FLAG-hAT1R-KPVAT-Venus plasmid was created from pcDNA3/SP-FLAG-hAT1R-WT that was amplified by PCR using the forward primer $5^{\prime}$-CCTAGCTAG CTCGAGGCCACCATGAACACGATCATC- $3^{\prime}$ and reverse primer 5'-TACCGGTGGCGACCGGTTTCTCAACCTCAA AACATGGTGC-3' (without a stop codon). The purified PCR fragment obtained was then subcloned in-frame into the NheI and AgeI restriction sites located in $5^{\prime}$ and $3^{\prime}$, respectively, of pcDNA3.1/Venus, which was a kind gift from Dr. Michel Bouvier (Université de Montreál, Montréal, Canada). In a same way, the pcDNA3.1/SP-FLAG-hAT1R[ $\Delta 325]-K P V A T-V e n u s$ plasmid was generated using the forward primer $5^{\prime}$-CCTAGCT AGCTCGAGGCCACCATGAACACGATCATC- $3^{\prime}$ and reverse primer $\quad 5^{\prime}$-AAAGGGTGGCGACCGGTTTGGCTTTTGGGG GAATATATTTTAGAAGCTG-3' (without a stop codon) to amplified pcDNA3/SP-FLAG-hAT1R-WT, and the resulting PCR fragment was then subcloned into the same restriction sites of pcDNA3.1/Venus. The HA-hOTR-Venus plasmid was made by the PCR amplification of a previously described hOTR-YFP construct (21) using the forward primer 5'-TTATGCCTGC GGATCCGAGGGCGCGCTCGCAGCCAACT-3' and reverse primer $\quad 5^{\prime}$-CGCCACCTCCGGATCCCGCCGTGGATGGCT GGGA-3'. The purified PCR fragment obtained was then digested at the BamHI restriction site, and subcloned in-frame by recombination into pIRESpuro3/HA-Venus using the InFusion cloning system from Clontech Laboratories (Mountain View, CA, USA). The pcDNA3.1/SP-HA-hFP-WT plasmid was prepared by two rounds of PCR. First, a previously described pIRESpuro3/HA-hFP-WT construct (18) was amplified using the forward primer $5^{\prime}$-ATGAACACGATCATCGCCCTGA GCTACATCTTCTGCC- $3^{\prime}$ and reverse primer 5'-ATCC
GAATTCCTAGGTGCTTGCTGATTTCTCTGC-3' . The purified PCR fragment was submitted to a second round of PCR amplification using the forward primer $5^{\prime}$-CCTAGCTAGC TCGAGGCCACCATGAACACGATCATC- $3^{\prime}$ and the same reverse primer. The resulting PCR fragment was then purified and digested at the XhoI and EcoRI restriction sites located at the $5^{\prime}$ and $3^{\prime}$, respectively, and subcloned into pcDNA3.1 from Invitrogen (Waltham, MA, USA). The pcDNA3.1/SP-HA-hFPKPVAT-Venus plasmid was produced using the forward primer 5'-CCTAGCTAGCTCGAGGCCACCATGAACACGATCATC$3^{\prime}$ and reverse primer 5'-GGTGGCGACCGGTTTGGTGCTTG CTGATTTTGC-3' to amplify pcDNA3.1/SP-HA-hFP-WT by PCR. The purified PCR fragment was then digested at the NheI and AgeI restriction sites located in $5^{\prime}$ and $3^{\prime}$, respectively, and subcloned into pcDNA3.1/Venus. All constructs were verified by bidirectional DNA sequencing. The constructs for enhanced bystander BRET to examine AT1R and FP trafficking, Lyn-rGFP, and rGFP-FYVE were used as previously described (17).

\section{Cell Culture and Transient Transfection}

The HEK 293 parental and $\Delta \mathrm{G} \alpha_{\mathrm{q} / 11 / 12 / 13}$ cell lines were cultured in $75 \mathrm{~cm}^{2}$ plastic flasks containing Dulbecco's Modified Eagle's Medium (DMEM) high glucose supplemented with $5 \%(\mathrm{v} / \mathrm{v})$ fetal bovine serum (FBS) and 1\% (w/v) penicillin-streptomycin (P-S) antibiotics. Cells were cultured in a controlled, humidified environment maintained at $37^{\circ} \mathrm{C}$ and $5 \% \mathrm{CO}_{2}$ atmosphere until a confluency of $80-100 \%$ was reached. For transfection, cells were trypsinized, and 125,000 cells/well in $1 \mathrm{~mL}$ of the same fresh media were seeded into 12 -well plates. Cells were incubated overnight in at $37^{\circ} \mathrm{C}$. After $24 \mathrm{~h}$, media from the plate was replaced by $1 \mathrm{~mL} /$ well of DMEM supplemented with $5 \%(\mathrm{v} / \mathrm{v})$ FBS. Cells were transfected with the appropriate plasmids encoding for AT1R $(0.3 \mu \mathrm{g} /$ well $)$, FP (0.1 $\mu \mathrm{g} /$ well $)$, and the sensors ( $\beta$-arrestin 1/2-RlucII $(0.0025-0.025 \mu \mathrm{g} /$ well), along with pcDNA3.1(-) for a total of $1.0 \mu \mathrm{g}$ per well using Lipofectamine ${ }^{\circledR} 2000$ [2.5(Lipo2000):1(DNA) ratio] and following the manufacturer's instructions. Twenty-four hours post-transfection, the cells were trypsinized, and 40,000-50,000 cells/well were transferred into white 96-well plates (Costar ${ }^{\circledR}$ \#3917, Corning, NY, USA) previously coated with poly-Lornithine hydrobromide (Sigma-Aldrich Inc., St. Louis, MO, USA). Cells were left in a cell culture incubator for another $24 \mathrm{~h}$ before performing the experiments. Mycoplasma testing was carried out periodically on all cell lines using the MycoAlertTM kit from Lonza (Rockland, MD, USA).

\section{Bioluminescence Resonance Energy Transfer (BRET) Assay}

BRET experiments were performed as described elsewhere (13, 14, 18, 22, 23). For intermolecular BRET experiments, energydonor proteins were fused to Renilla luciferase (Rluc) II and energy-acceptor proteins were fused to the yellow florescent protein (YFP). In all experiments, coelenterazine $h$ was used as the Rluc/RlucII substrate to generate light with a maximal emission peak at $480 \mathrm{~nm}$, allowing YFP excitation. In a typical experiment, transfected cells from a white 96-well plate were carefully washed once with $150 \mu \mathrm{L}$ of Kreb's buffer [146 mM 
$\mathrm{NaCl}, 4.2 \mathrm{mM} \mathrm{KCl}, 0.5 \mathrm{mM} \mathrm{MgCl}_{2}, 1 \mathrm{mM} \mathrm{CaCl}_{2}, 5.9 \mathrm{mM}$ glucose, and $10 \mathrm{mM}$ HEPES $\mathrm{pH} 7.4,0.1 \%(\mathrm{v} / \mathrm{v})$ glucose], and then the cells were incubated in the absence (i.e., with only Kreb's buffer alone) or presence (i.e., with $\mathrm{AT}_{1} \mathrm{R}$ antagonists or endocytosis inhibitors) of pretreatments in $95 \mu \mathrm{L} /$ well of the same fresh Kreb's buffer. The plate was protected from light, and the cells were incubated for $1 \mathrm{~h}$ at $37^{\circ} \mathrm{C}$ for BRET experiments which were conducted at $37^{\circ} \mathrm{C}$. A TriStar ${ }^{2}$ LB 942 multimode microplate reader from Berthold Technologies Inc. (Bad Wildbad, 75323, Germany) equipped with the predetermined BRET1 filter pair F485/F530, and a VICTOR X-light multilabel plate reader from Perkin Elmer Inc. (Waltham, MA, USA) equipped with the predetermined BRET1 filter pair F460/F535 nm (200 msec./filter, alternatively) were used to measure BRET ratios. For enhanced bystander BRET we used $410 \mathrm{~nm}$ (donor) and 515/40 nm (acceptor) filters. Under these conditions, both plate readers were able to complete one cycle of BRET ratio measurement in $2 \mathrm{~min}$ for a 96-well plate. Experiments with 96-well plates were also carried out at once following four consecutive steps in a timely fashion so that a same time interval apply between each well throughout the process: (1) adding the coelenterazine h substrate for light generation (using a repeater pipette); (2) measuring the BRET ratios of basal, unstimulated cells; (3) stimulating the cells with either vehicle or ligand (using a multichannel pipette); (4) measuring the BRET ratios of stimulated, ligand-induced cells. Following a $1 \mathrm{~h}$ incubation in Krebs buffer, $25 \mu \mathrm{L} /$ well of a $30 \mu \mathrm{M}$ coelenterazine h solution (for a final concentration of $5 \mu \mathrm{M}$ ) was sequentially added to the cells so it takes $2 \mathrm{~min}$ to fill up the entire 96-well plate. The basal, unstimulated BRET ratios were then immediately measured over a period of $10 \mathrm{~min}$ ( 5 measuring cycles). Upon completion, the 96-well plate was rapidly removed from the plate reader, and $30 \mu \mathrm{L} /$ well of either vehicle or $5 \mu \mathrm{M}$ ligand (e.g., Ang II or PGF2 $\alpha$, for a final concentration of $1 \mu \mathrm{M}$ in $150 \mu \mathrm{L}$ ) was sequentially added to the cells so, again, it takes $2 \mathrm{~min}$ to fill up the entire 96-well plate. The ligand-induced BRET ratios were then immediately measured over a period of $90 \mathrm{~min}$ (45 measuring cycles).

\section{Data Analysis}

BRET ratios were calculated as BRET $=\lambda_{530 \text { or } 535} / \lambda_{485}$ or 460 , and ligand-induced BRET changes as $\triangle \mathrm{BRET}=\mathrm{BRET}_{\text {Ligand }}-$

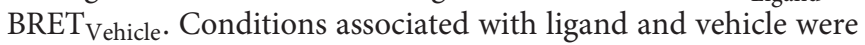
performed in triplicate (i.e., 3-wells each) for each biological replicate, and averaged data were used in all calculations. As shown in the figures, BRET data were reported as kinetic traces or bar graphs integrating the area under the curve. Statistical analysis and curve fitting were all carried out using the GraphPad PRISM software v6.0 (La Jolla, CA, USA). For Figure 1, half-time values were calculated using a one-phase association equation and a least squares method to fit the data on a curve by non-linear regression. For Figure 2, $\triangle B R E T$ data were fit on a curve by non-linear regression using a one-phase exponential dissociation decay and a least squares method. Statistical analysis on normalized $\triangle$ BRET data was performed using a MannWhitney $U$-test $(p<0.05)$, followed by a post-hoc Dunn's test to correct for multiple comparisons (all conditions vs. $0 \mu \mathrm{g}$ ). For Figure 4 statistical analysis on $\triangle B R E T$ data was performed
TABLE 1 | EC 50 values for $\beta$-arrestin 2-Rlucll recruitment to the AT1R-Venus/FP-WT dimer.

\begin{tabular}{lc}
\hline & EC $_{50}$ \\
\cline { 2 - 2 } & Mean \pm SEM \\
\hline PGF2 $\alpha$ & $7.2 \times 10^{-9} \pm 6.9 \times 10^{-10}$ \\
AL-8810 & $3.0 \times 10^{-6} \pm 1.6 \times 10^{-6}$ \\
Cloprostenol & $1.8 \times 10^{-10} \pm 5.2 \times 10^{-11}$ \\
Fluprostenol & $8.9 \times 10^{-10} \pm 7.2 \times 10^{-11}$ \\
Latanoprost & $6.1 \times 10^{-9} \pm 1.2 \times 10^{-9}$ \\
Tafluprost & $4.8 \times 10^{-10} \pm 1.1 \times 10^{-10}$ \\
\hline
\end{tabular}

HEK 293 parental cells transiently expressing $\beta$-arrestin 2-Rlucll, AT1R-Venus, and FPWT dimer were assayed as described in section Materials and Methods. Data represent mean \pm s.e.m. of independent experiments performed in triplicate $(n=3)$.

using an unpaired Student's $t$-test $(p<0.01)$, followed by a post-hoc Bonferroni test to correct for multiple comparisons (all conditions vs. PGF2 $\alpha$ or cloprostenol). $\mathrm{EC}_{50}$ values from Table 1 were calculated with the following three parameter equation: Response $=$ Bottom $+\left[(\right.$ Top - Bottom $) /\left(1+10\left(\log \mathrm{EC}_{50}\right.\right.$ $-\log [\mathrm{A}])]$, where Top and Bottom represented maximal and minimal asymptotes of the curve, $[\mathrm{A}]$ is the agonist concentration expressed in $(\mathrm{M})$ and $\mathrm{EC}_{50}$ is the agonist concentration $(\mathrm{M})$ that generated a response half way between the top and bottom.

\section{RESULTS}

\section{Symmetric and Asymmetric $\beta$-Arrestin Recruitment Mediated by Ang II and PGF2 $\alpha$, Respectively}

We used BRET-based biosensors to examine real-time recruitment of $\beta$-arrestin 1/2-RlucII to AT1R-Venus alone, FP-Venus alone, and the $\mathrm{AT}_{1} \mathrm{R} / \mathrm{FP}$ dimer wherein Venus was fused to either AT1R or FP. Ang II stimulation induced a rapid, robust, and sustained $\beta$-arrestin 1/2-Rluc recruitment to $\mathrm{AT}_{1} \mathrm{R}-$ Venus alone (Figure $\mathbf{1 A}$ ) typical of a class-B GPCR interaction with $\beta$-arrestin (24). While showing an identical kinetic profile, co-expression of FP-WT to form the putative AT1R-Venus/FP-WT dimer dampened the extent of $\beta$-arrestin recruitment (Figure 1A). However, we cannot say with certainty that this effect is not due to reduced AT1R expression in the presence of co-expressed FP or simply a different physical spacing of BRET donor and acceptor caused by formation of the heterodimer. $\beta$-arrestin recruitment could blocked by the AT1R antagonist losartan and was not detected using a mutated AT1R[ $\Delta 325]$-Venus with a markedly reduced ability to recruit $\beta$-arrestin (Figure 1B). On the other hand, in the AT1R-WT/FP-Venus dimer configuration, however, Ang II failed to recruit $\beta$-arrestin 1/2-Rluc (Figure 1A). Altogether, these findings suggest that Ang II occupancy of the AT1R/FP dimer induced a recruitment of $\beta$-arrestin $1 / 2$ that is symmetric, or cis, to the AT1R protomer, and that FP may act to reduce this response. By way of comparison, PGF $2 \alpha$ stimulation did not induce recruitment of $\beta$-arrestin $1 / 2$-Rluc to FP alone, as previously shown $(25,26)$, or to the AT1R-WT/FP-Venus dimer 


\section{A Ang II-Induced $\beta$ Arr1/2-Rlucll Recruitment}

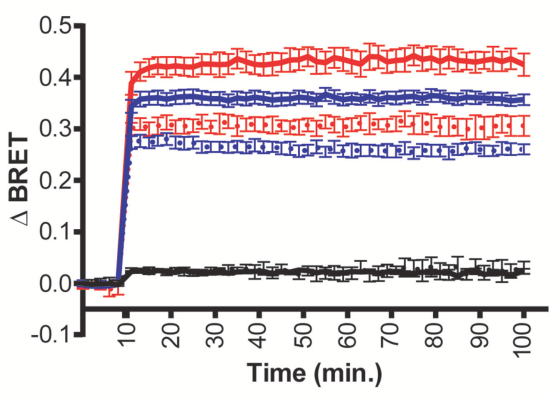

... AT ${ }_{1}$ R-Venus / $\beta$ Arr1-Rlucll

- AT 1 R-Venus / $\beta$ Arr2-Rlucll

... AT 1 R-Venus/FP-WT / $\beta$ Arr1-Rlucll

- $A T_{1}$ R-Venus/FP-WT / $\beta$ Arr2-Rlucll

... AT 1 R-WT/FP-Venus / $\beta$ Arr1-Rlucll

- $\mathrm{AT}_{1}$ R-WT/FP-Venus / $\beta$ Arr2-Rlucll
B Ang II-Induced $\beta$ Arr1/2-Rlucll Recruitment

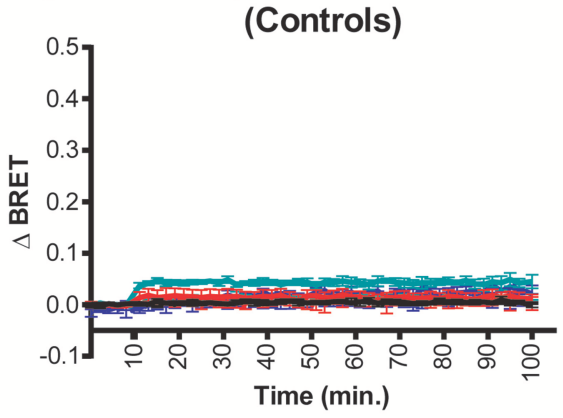

‥ AT ${ }_{1}$ R-Venus/FP-WT + Losartan / $\beta$ Arr1-Rlucll

- $A T_{1}$ R-Venus/FP-WT + Losartan / $\beta$ Arr2-Rlucll

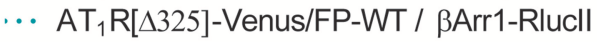

- $A T_{1} R[\Delta 325]-V e n u s / F P-W T / \beta$ Arr2-Rlucll

... FP-Venus / $\beta$ Arr1-Rlucll

- FP-Venus / $\beta$ Arr2-Rlucll

-.. BArr1-Rlucll

- $\beta$ Arr2-Rlucll

\section{C}

\section{PGF2 $\alpha$-Induced $\beta$ Arr1/2-Rlucll Recruitment}

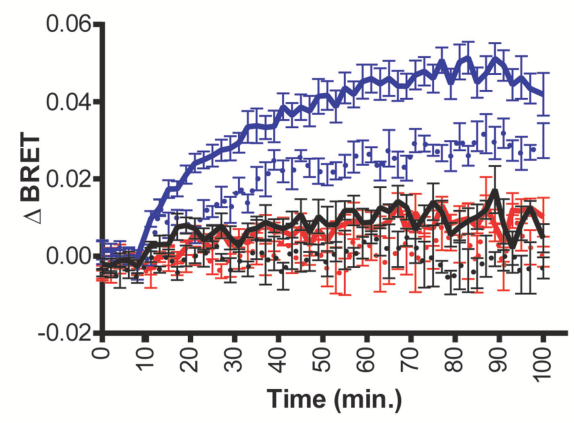

... FP-Venus / $\beta$ Arr1-Rlucll

- FP-Venus / $\beta$ Arr2-Rlucll

... AT ${ }_{1}$ R-Venus/FP-WT / $\beta$ Arr1-Rlucll

- $\mathrm{AT}_{1}$ R-Venus/FP-WT / $\beta$ Arr2-Rlucll

... AT AT $_{1}$ R-WT/FP-Venus / $\beta$ Arr1-Rlucll

- AT ${ }_{1}$ R-WT/FP-Venus / BArr2-Rlucll
D

\section{PGF2 $\alpha$-Induced $\beta$ Arr1/2-Rlucll Recruitment} (Controls)

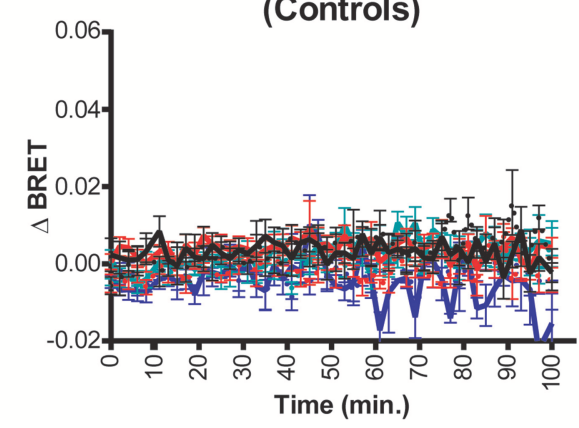

... OTR-Venus/FP-WT / $\beta$ Arr1-Rlucll

- OTR-Venus/FP-WT / $\beta$ Arr2-Rlucll

... AT ${ }_{1} R[\Delta 325]-$ Venus/FP-WT / $\beta$ Arr1-Rlucll

- $\mathrm{AT}_{1} \mathrm{R}[\Delta 325]-$ Venus/FP-WT / $\beta$ Arr2-Rlucll

... $\mathrm{AT}_{1} \mathrm{R}$-Venus / $\beta$ Arr1-Rlucll

- $A T_{1}$ R-Venus / $\beta$ Arr2-Rlucll

... $\beta$ Arr1-Rlucll

- $\beta$ Arr2-Rlucll

FIGURE 1 | Symmetric and asymmetric recruitment of $\beta$-arrestin $1 / 2$ to the AT1R/FP dimer by Ang $\|$ and PGF2 $\alpha$, respectively. (A) Ang II (1 $\mu \mathrm{M})$ induced a rapid and sustained symmetric recruitment of $\beta$-arrestin 1 -Rlucll (dashed lines; $\mathrm{t}_{1 / 2}<2$ min.) and $\beta$-arrestin 2 -Rlucll (full lines; $\mathrm{t}_{1 / 2}<2$ min) to AT1R-Venus alone (purple lines) and to a lesser extent, the AT1R-Venus/FP-WT dimer (blue lines), but not to the AT1R-WT/FP-Venus dimer (black lines). (B) No and very small responses were detected with Ang II by blocking AT1R-Venus with losartan (100 $\mu \mathrm{M})$ (dashed and full blue lines), and when an AT1R[ $\Delta 325]$-Venus mutant deficient for both $\beta$-arrestin 1/2-Rlucll recruitments (dashed and full blue-green lines) were used in the context of the dimer, respectively. Responses were all specific to AT1R since no responses were detected for FP-Venus alone (dashed and full red lines) and $\beta$-arrestin 1/2-Rlucll alone (dashed and full black lines). (C) PGF2 $\alpha$ (1 $\mu$ M) induced a slower, yet sustained asymmetric recruitment of $\beta$ arr1-Rlucll (dashed blue lines; $t_{1 / 2}=20 \mathrm{~min}$ ) and $\beta$-arrestin 2-Rlucll (full blue lines; $\mathrm{t}_{1 / 2}=17 \mathrm{~min}$ ) to the AT1R-Venus/FP-WT dimer only, but not to FP-Venus alone (dashed and full red lines) and the AT1R-WT/FP-Venus dimer (dashed and full black lines). (D) No responses were detected with PGF2 $\alpha$ when OTR-Venus (dashed and full blue lines) and an AT1R[ $\Delta 325]$-Venus mutant deficient for both $\beta$-arrestin 1/2-Rlucll recruitment (dashed and full blue-green lines) were used in the context of the dimer. Responses were all specific to FP since no responses were detected for AT1R-Venus (dashed and full red lines) and $\beta$-arrestin 1/2-Rlucll alone (dashed and full black lines). Data represent mean \pm s.e.m. of independent experiments [biological replicates, each performed in triplicate $(n=3-15)]$. 


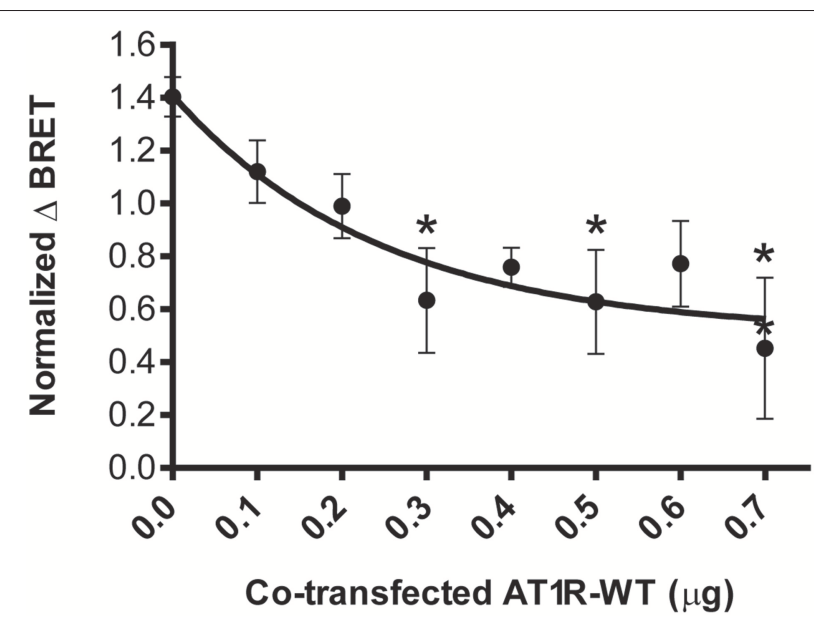

FIGURE 2 | Specificity of the PGF2 $\alpha$-induced $\beta$-arrestin 2 recruitment to the AT1R/FP dimer. The recruitment of $\beta$-arrestin 2-Rlucll to the AT1R-Venus $(0.3$ $\mu \mathrm{g}) / \mathrm{FP}-\mathrm{WT}(0.1 \mu \mathrm{g})$ dimer (fixed amount) induced by PGF2 $\alpha(1 \mu \mathrm{M})$ was titrated by co-transfecting increasing amounts of AT1R-WT $(0.0-0.7 \mu \mathrm{g})$. Increased expression of AT1R-WT competed with AT1R-Venus for dimerization with FP-WT, reducing the capacity of the AT1R-Venus/FP-WT dimer to recruit $\beta$-arrestin 2-Rlucll. Data were normalized for AT1R-Venus expression and represent mean \pm s.e.m. of independent experiments [biological replicates each performed in triplicate $(n=3-5)]$. ${ }^{*} p<0.05$, compared to AT1R-WT $(0.0 \mu \mathrm{g})$.

(Figure 1C). Interestingly, however, it induced a comparatively slower, less robust, yet prolonged $\beta$-arrestin 1/2-Rluc recruitment to the AT1R-Venus/FP-WT than Ang II did, suggesting this time that the PGF2 $\alpha$ occupancy of FP recruits $\beta$-arrestin $1 / 2$ to its AT1R partner protomer in an asymmetrical, or trans, fashion (Figure 1C). Recruitment of $\beta$-arrestin was not seen when FP-WT was co-expressed in the context of a dimer with $\beta$-arrestin $1 / 2$ recruitment-deficient AT1R[ $\Delta 325]$-Venus mutant or another peptidergic class-A GPCR, the oxytocin (OT) receptor (OTR, Figure $1 D$ ). We previously showed that OTR does not dimerize with FP (13) so results presented here are consistent with this earlier study. In all cases, $\beta$-arrestin 2 was shown to be a better responder than $\beta$-arrestin 1 for both Ang II and PGF $2 \alpha$ stimulation (Figures 1A,C). All responses were also specific since no recruitment was detected when $\mathrm{AT}_{1} \mathrm{R}$ alone or FP alone were stimulated with their non-cognate ligands (Figures 1B,D), or when $\beta$-arrestin 1/2-RlucII were transfected alone. Furthermore, the PGF $2 \alpha$-induced recruitment of $\beta$-arrestin 2-RlucII to the AT1R-Venus/FP-WT dimer was titrated by coexpression of increasing amounts of AT1R-WT to disrupt the reporting dimer by competition, demonstrating the specificity of AT1R-Venus/FP-WT dimer formation critical for asymmetric recruitment of $\beta$-arrestin 2 (Figure 2 ).

In order to provide an independent measure of how the dimer resulted in a new ability for FP to induce trafficking of the AT1R/FP dimer, we used enhanced bystander BRET (17) to follow association of AT1R-RlucII or FP-RlucII with a membrane BRET acceptor (Lyn-rGFP) or early endosome acceptor (rGFPFYVE). In the case where AT1R-RlucII was co-expressed with WT FP and either of the BRET acceptors, stimulation with either Ang II (Figure 3A) or PGF2 $\alpha$ (Figure 3B) led to a timedependent loss of the membrane signal and an increase in the endosomal population. When FP-RlucII was co-expressed with WT-AT1R and the two BRET acceptors, again PGF2 $\alpha$ induced a loss of membrane-localized receptor and a transient increase in an early endosomal population (Figure 3C). This suggests that the two ligands might drive receptors into different trafficking itineraries, discussed below. We also attempted to measure what would happen when we stimulated this combination of receptors (FP-RlucII and WT-AT1R) with Ang II. There was little change in bystander BRET for either location-specific biosensor likely because in our hands the AT1R expresses so much better than the FP and thus most of the AT1R in this configuration was not coupled to FP (data not shown).

Next, we assessed to what extent the AT1R-Venus/FP-WT dimer could asymmetrically recruit the $\beta$-arrestin 2 -Rluc by examining a panel of five chemically distinct FP ligands, some of which have clinical indications (27). Except for AL-8810, all the ligands we tested, cloprostenol, fluprostenol, latanoprost, and tafluprost, were found to recruit $\beta$-arrestin 2-Rluc in an asymmetric fashion with $\mathrm{EC}_{50}$ values in the low nanomolar to the picomolar range (Table 1). While all the other tested ligands exhibit full agonist properties, AL-8810 is the only one shown to display partial agonist properties (28), and had an $\mathrm{EC}_{50}$ value for $\beta$-arrestin 2-RlucII recruitment in the micromolar range (Table 1). Further, as AL-8810 promotes activation of ERK1/2 by transactivation of the epidermal growth factor receptor (25), this may be possible explanation for this discrepancy. It is clear, however, that a number of FP ligands can recruit $\beta$-arrestin to the dimer.

Having previously shown allosteric crosstalk between FP and AT1R in that antagonists for either receptor modulated signaling via the partner receptor, we next tested how different AT1R antagonists modulated PGF $2 \alpha$-mediated recruitment of $\beta$-arrestin to the dimer. PGF $2 \alpha$ responses were regulated by both temilsartan and azilsartan (Figure 4A), while cloprostenol responses were regulated by temilsartan only (Figure 4B). On the other hand, other AT1R antagonists we tested, irbesartan, candersartan, and losartan, did not allosterically modulate the responses induced by either PGF2 $\alpha$ or cloprostenol.

\section{G Proteins Alter the Extent of $\beta$-Arrestin Recruitment}

Using a HEK 293 line with deletion of $\mathrm{G}_{\mathrm{q} / 11}$ and $\mathrm{G}_{12 / 13}$ (13), we next assessed how different $G$ proteins might be involved in recruitment of $\beta$-arrestin to the FP/AT1R dimer. Ang II-induced recruitment of $\beta$-arrestin 1/2-RlucII to the $\mathrm{AT}_{1} \mathrm{R}$-Venus/FP-WT dimer was measured in the parental and the $\Delta \mathrm{G} \alpha_{\mathrm{q} / 11 / 12 / 13}$ cell line. The absence of $\mathrm{G}$ proteins reduced Ang II-induced response by approximately $50 \%$ for $\beta$-arrestin 1 and $\beta$-arrestin 2 (Figures 5A,B). Individual $G$ proteins were then restored to the $\Delta \mathrm{G} \alpha_{\mathrm{q} / 11 / 12 / 13}$ cell line to assess which might be able to rescue this loss of $\beta$-arrestin recruitment. Replacement of $\mathrm{G} \alpha_{11}, \mathrm{G} \alpha_{12}$, or $\mathrm{G} \alpha_{13}$ partially rescued $\beta$-arrestin 1 recruitment but surprisingly, not $\mathrm{G \alpha}_{\mathrm{q}}$ (Figure 5A). A similar finding was noted for $\beta$-arrestin 2 (Figure 5B). Although the data were considerably noisier for 


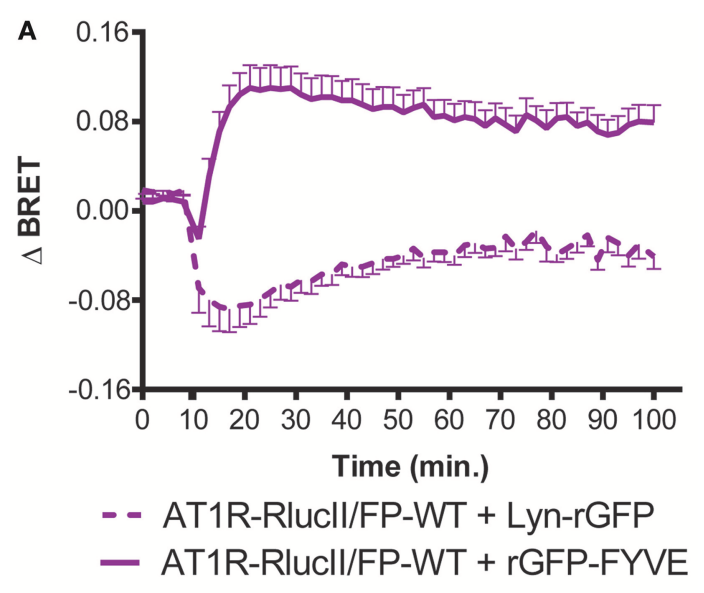

B

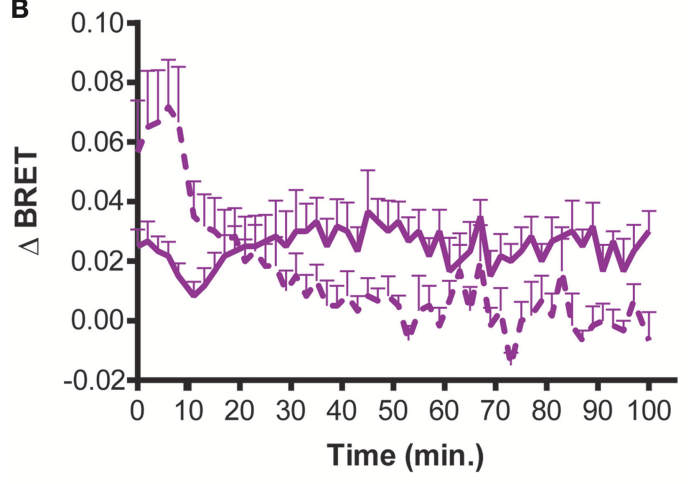

- - AT1R-Rlucl//FP-WT + Lyn-rGFP

- AT1R-Rlucl//FP-WT + rGFP-FYVE

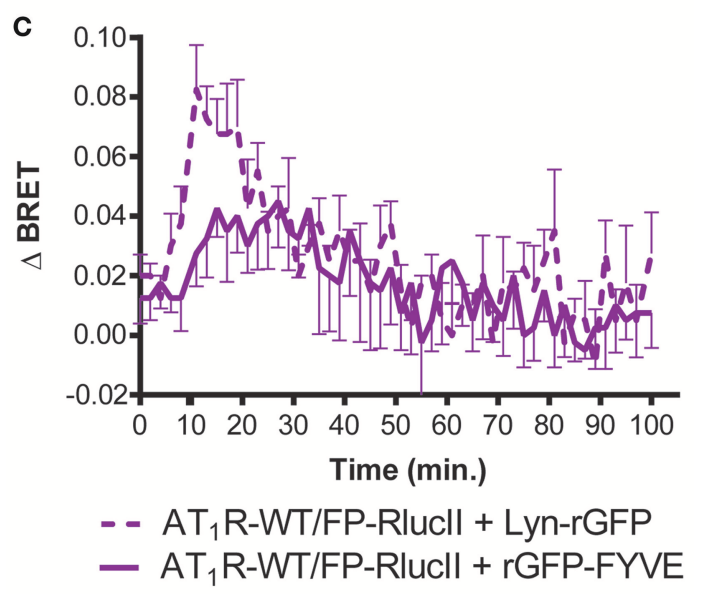

FIGURE 3 | Enhanced bystander BRET shows FP can stimulate AT1R internalization. HEK293 cells were transfected with the indicated enhanced BRET pairs. To monitor AT1R- or FP-mediated trafficking of AT1R-Rlucll from the membrane (loss of Lyn-rGFP bystander BRET) or endosomal trafficking (as measured by increase in rGFP-FYVE bystander BRET), AT1R-Rlucll were co-transfected with wildtype FP and the indicated bystander BRET partner. Cells were stimulated with (A) $1 \mu \mathrm{M}$ Ang $\|$ or (B) $1 \mu \mathrm{M}$ PGF2 $\alpha$ and monitored over time. (C) FP-Rlucll were co-transfected with wildtype AT1R and the

(Continued)
FIGURE 3 | indicated bystander BRET partner and stimulated with $1 \mu \mathrm{M}$ PGF2 $\alpha$ and monitored over time. BRET signals were measured as described in Materials and Methods. Data represent mean \pm s.e.m. of independent experiments performed in triplicate $(n=3)$.

the responses measured after treatment with PGF2 $\alpha$, similar patterns were detected for $\beta$-arrestin 1 recruitment (Figure 5C, also see inset). Interestingly, in this case, re-expression of any of the four $\mathrm{G} \alpha$ subunits was able to partially rescue $\beta$-arrestin 2 recruitment mediated by PGF2 $\alpha$ (Figure 5D). Although we did not control for expression of the different $G$ protein subunits, these data suggest a complicated interplay between $\mathrm{G}$ protein and $\beta$-arrestin coupling, inconsistent with a simple interpretation of these events.

\section{Spatiotemporal Aspects of Differential $\beta$-Arrestin 1 Recruitment to the FP/AT1R Heterodimer}

We previously showed that stimulation of the receptor pair with either ligand resulted in receptor internalization of the dimer when reconstituted using a split Venus protein complementation (12). The data in that paper, using confocal imaging, hinted that distinct endocytic routes might be taken in response to PGF2 $\alpha$ compared to Ang II. Given the role of $\beta$-arrestin recruitment in the post-stimulation trafficking of receptors, we examined how different inhibitors of endocytosis affected interactions between the FP/AT1R heterodimer and $\beta$-arrestin1/2. As before, we first examined the effects of Ang II on $\beta$-arrestin $1 / 2$ recruitment. In both cases, neither concanavalin $\mathrm{A}$ or a dominant negative dynamin K44 mutant had significant effects compared to control (Figures 6A,B). However, the extent of the recruitment of $\beta$-arrestin was decreased significantly by phenylarsine oxide and potentiated by sucrose. The responses to PGF2 $\alpha$ were qualitatively different. In this case, again there was no effect of dynamin $\mathrm{K} 44$, but both sucrose and phenylarsine oxide reduced $\beta$-arrestin $1 / 2$ recruitment while concanavalin A potentiated the interaction (Figures 6C,D). These results again suggest that the trafficking itineraries of the heterodimer are distinct following stimulation with either Ang II or PGF2 $\alpha$. Taken together our data suggest that the dimer adopts different fates when stimulated by distinct ligands.

\section{DISCUSSION}

Here, we show that two ligands binding to different sites in a GPCR heterodimer elicit asymmetric responses with respect to $\beta$-arrestin $1 / 2$ recruitment. Although FP does not normally recruit $\beta$-arrestin1/2 $(12,26)$, as there are GPCRs that don't recruit $\beta$-arrestin (29), stimulation of FP can recruit $\beta$-arrestin to an AT1R partner in the context of a heterodimer. Further, we show that different ligands acting on receptor dimers may lead to qualitatively distinct $\beta$-arrestin $1 / 2$ recruitment events with potentially distinct trafficking itineraries. Such observations might help to explain the functional asymmetries weve noted in our previous study (12). Our data add a new wrinkle to signaling via GPCR heterodimers, when we consider how structural and 
A

PGF2 $\alpha$

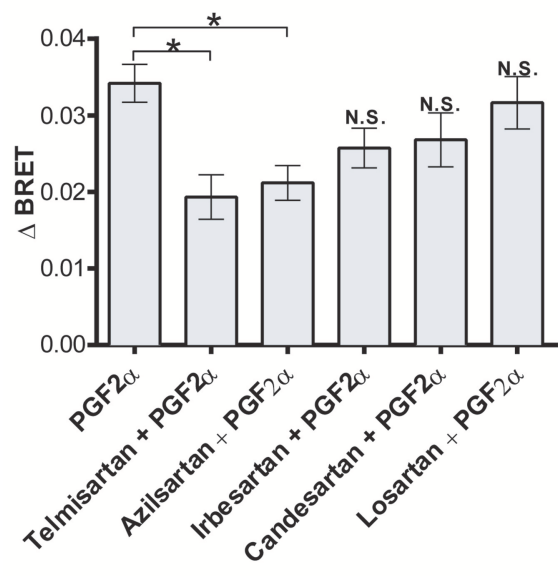

B
Cloprostenol

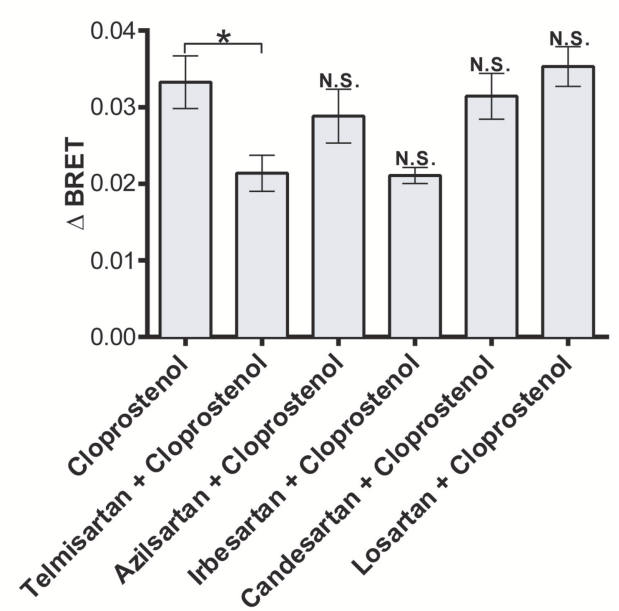

FIGURE 4 | Biased allosteric regulation of the PGF2 $\alpha$ - and cloprostenol-induced $\beta$-arrestin2 recruitment to the AT 1 R/FP dimer by AT1R antagonists. (A) Pretreatment ( $1 \mu \mathrm{M}$ for $30 \mathrm{~min}$ ) with telmisartan or azilsartan allosterically inhibited recruitment of $\beta$-arrestin 2-Rlucll to the AT1R-Venus/FP-WT dimer in response to PGF2 $\alpha$ ( $1 \mu \mathrm{M})$. Under the same experimental conditions, irbesartan, candersartan and losartan produced no allosteric effects. (B) Pretreatment (1 $\mu \mathrm{M}$ for 30 min) with telmisartan allosterically inhibited the recruitment of $\beta$-arrestin 2-Rlucll to the AT1R-Venus/FP-WT dimer in response to cloprostenol (1 $\mu$ M). Under the same experimental conditions, azilsartan, irbesartan, candersartan and losartan produced no allosteric effects. Data represent mean \pm s.e.m. of independent experiments [biological replicates performed in triplicate $(n=3-6)]$. ${ }^{*} p<0.05$. N.S., non-significant.

functional asymmetries might play out in terms of bi-directional allosteric receptor regulation.

Previously, we showed that the AT1R and FP formed heterodimers in both HEK 293 and vascular smooth muscle cells (VSMC) where they are endogenously co-expressed. We analyzed several phenotypic responses, including MAPK activation and DNA and protein synthesis in both HEK 293 cells and in VSMC. We showed AT1R when treated with an antagonist strongly potentiated ERK1/2 activation by FP, which was not reciprocated by treatment of FP with its own antagonists when measuring Ang II-mediated ERK1/2 activation (12). We also used $\left[{ }^{3} \mathrm{H}\right]$ thymidine incorporation as a measure of DNA synthesis, and $\left[{ }^{3} \mathrm{H}\right]$-leucine incorporation as a measure of protein synthesis and observed that pre-treatment of VSMC with an AT1R antagonist on $\left[{ }^{3} \mathrm{H}\right]$-thymidine incorporation following PGF2 $\alpha$ stimulation could be inhibited by FP blockade, but not by AT1R blockade. However, the FP antagonist was as efficient as the AT1R antagonist in inhibiting both Ang II-induced $\left[{ }^{3} \mathrm{H}\right]$ thymidine or $\left[{ }^{3} \mathrm{H}\right]$-leucine incorporation (12). These results highlighted an important asymmetry in the regulation of cellular responses via the receptor heterodimer. This was also reflected in our conformational profiling of both receptors using the FlAsH-BRET approach where conformational information could be transferred from the AT1R through to FP via a shared $G$ protein but the converse could not be detected. Distinct patterns of $\beta$-arrestin $1 / 2$ recruitment might be at the root of some of the functional asymmetries. Interestingly, a number of GPCR dimers have been demonstrated to recruit $\beta$-arrestin $1 / 2$ [reviewed in (30)], although whether asymmetries in $\beta$-arrestin $1 / 2$ recruitment, such as we have measured here have yet to be assessed systematically with respect to other homoor heterodimers.

Deletion of several $\mathrm{G} \alpha$ subunits significantly abrogated both Ang II- and PGF $2 \alpha$-mediated $\beta$-arrestin $1 / 2$ recruitment which was in all cases restored by re-expression of $G \alpha_{11}, G \alpha_{12}$, or $G \alpha_{13}$ but not always $\mathrm{G} \alpha_{\mathrm{q}}$. This is odd, as $\mathrm{G} \alpha_{\mathrm{q}}$ is a well-known partner for both receptors. We identified $\mathrm{G} \alpha_{\mathrm{q} / 11}$ as the conduit by which allosteric information was transferred from AT1R to FP which did not occur in the opposite direction from FP to AT1R (13). Perhaps this is a reflection of a similar asymmetry. It is also one of the rare instances where a distinction could be made between $\mathrm{G} \alpha_{11}$ and $\mathrm{G} \alpha_{\mathrm{q}}$. Recent studies have suggested we need to be circumspect about cells gene-deleted for different $G$ proteins that may get "rewired" as a consequence (31). More systematic studies with better controlled levels of $\mathrm{G}$ protein expression would be necessary to confirm our findings, but it is clear that changes to $\beta$-arrestin $1 / 2$ recruitment in the gene-deleted cells used in this study could be partially rescued by restoring individual $\mathrm{G} \alpha$ subunits.

We had previously shown that the trafficking of the putative heterodimer was likely different depending on whether stimulation was via Ang II or PGF2 $\alpha$ (12). We noted here that they had distinct sensitivities to different inhibitors of endocytic processes. In response to Ang II, the $\beta$-arrestin interaction was inhibited by phenylarsine oxide, a compound whose exact mechanism of action is unknown (32), and potentiated by hypertonic sucrose suggesting that in the latter case, more $\beta$-arrestin can be recruited 
A Ang II-Induced $\beta$ Arr1-Rlucll Recruitment

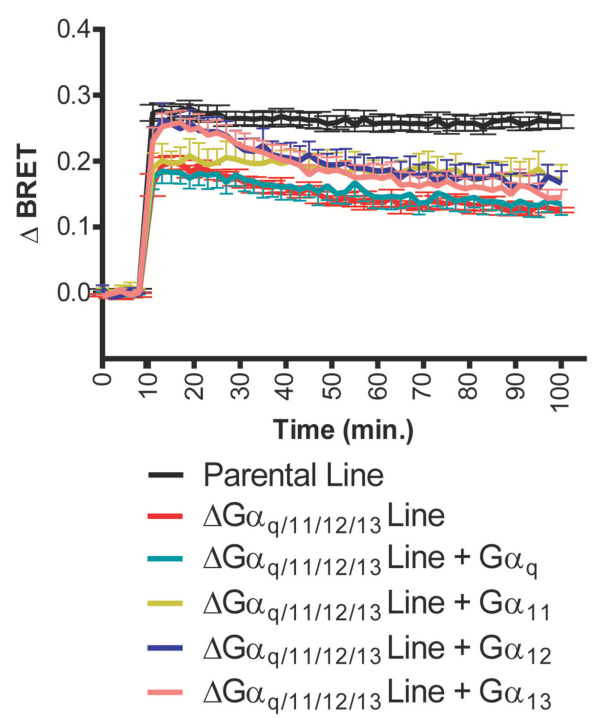

\section{C}

\section{PGF2 $\alpha$-Induced $\beta$ Arr1-Rlucll Recruitment}

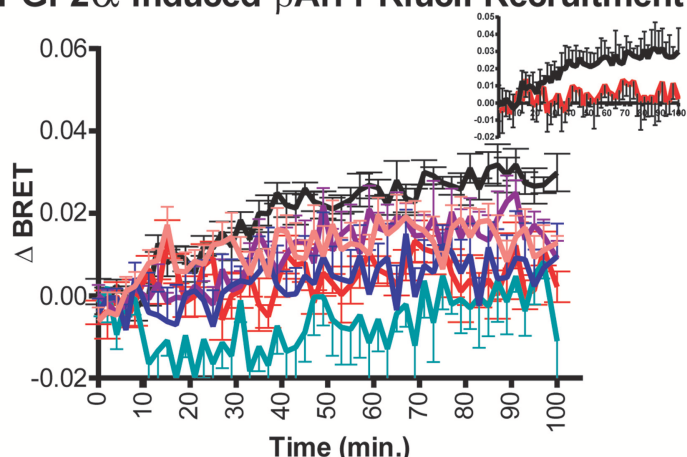

- Parental Line

- $\Delta \mathrm{G} \alpha_{\mathrm{q} / 11 / 12 / 13}$ Line

- $\Delta \mathrm{G} \alpha_{\mathrm{q} / 11 / 12 / 13}$ Line $+\mathrm{G} \alpha_{\mathrm{q}}$

- $\Delta \mathrm{G} \alpha_{\mathrm{q} / 11 / 12 / 13}$ Line $+\mathrm{G} \alpha_{11}$

- $\Delta \mathrm{G} \alpha_{\mathrm{q} / 11 / 12 / 13}$ Line $+\mathrm{G} \alpha_{12}$

$-\Delta G \alpha_{q / 11 / 12 / 13}$ Line $+G \alpha_{13}$
B Ang II-Induced $\beta$ Arr2-Rlucll Recruitment

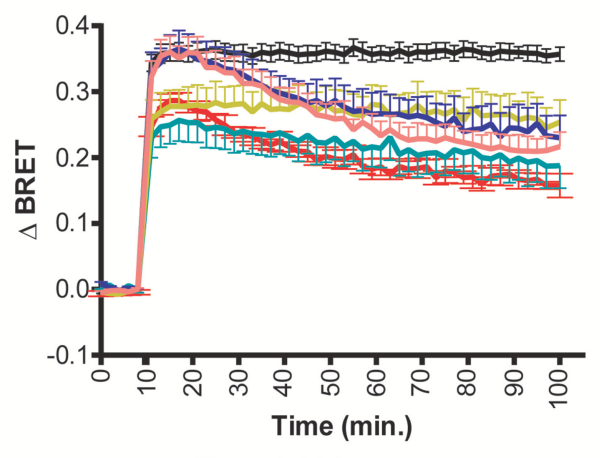

- Parental Line

$-\Delta \mathrm{G} \alpha_{\mathrm{q} / 11 / 12 / 13}$ Line

- $\Delta \mathrm{G} \alpha_{\mathrm{q} / 11 / 12 / 13}$ Line $+\mathrm{G} \alpha_{\mathrm{q}}$

- $\Delta \mathrm{G} \alpha_{\mathrm{q} / 11 / 12 / 13}$ Line $+\mathrm{G} \alpha_{11}$

- $\Delta \mathrm{G} \alpha_{\mathrm{q} / 11 / 12 / 13}$ Line $+\mathrm{G} \alpha_{12}$

$-\Delta \mathrm{G} \alpha_{\mathrm{q} / 11 / 12 / 13}$ Line $+\mathrm{G} \alpha_{13}$

\section{D}

\section{PGF2 $\alpha$-Induced $\beta$ Arr2-Rlucll Recruitment}

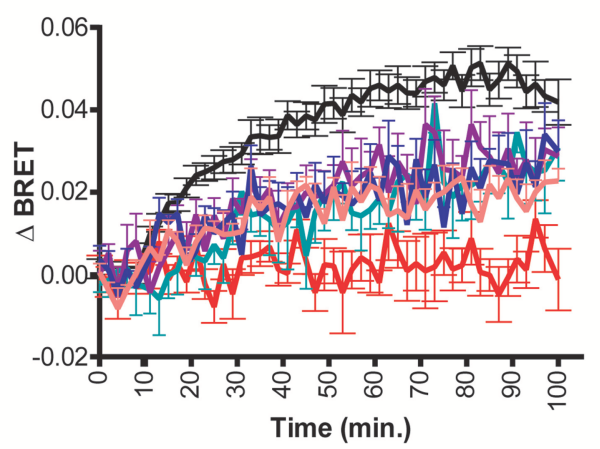

- Parental Line

- $\Delta G \alpha_{\mathrm{q} / 11 / 12 / 13}$ Line

- $\Delta G \alpha_{q / 11 / 12 / 13}$ Line $+G \alpha_{q}$

- $\Delta G \alpha_{q / 11 / 12 / 13}$ Line $+G \alpha_{11}$

- $\Delta G \alpha_{q / 11 / 12 / 13}$ Line $+G \alpha_{12}$

$-\Delta G \alpha_{q / 11 / 12 / 13}$ Line $+G \alpha_{13}$

FIGURE 5 | Role of G proteins in Ang II- and PGF2 $\alpha$-induced $\beta$-arrestin 1/2 recruitment to the AT1R/FP dimer. (A,B) Compared to the HEK 293 parental cell line (black lines), Ang II (1 $\mu \mathrm{M})$ induced a decaying and much lower, yet sustained recruitment of $\beta$-arrestin 1/2-Rlucll to the AT1R-Venus/FP-WT dimer when evaluated in the HEK $293 \Delta G \alpha_{\mathrm{q} / 11 / 12 / 13}$ cell line (red lines). (C,D) PGF2 $\alpha(1 \mu \mathrm{M})$ induced the recruitments of $\beta$-arrestin 1/2-Rlucll to the AT1R-Venus/FP-WT dimer in the HEK 293 parental cell line (black lines) only, and virtually no responses were detected with the HEK $293 \Delta \mathrm{G} \alpha_{\mathrm{q} / 11 / 12 / 13}$ cell line (red lines) (C), inset: The response in parental and $\Delta \mathrm{Ga} \mathrm{q}_{/ 11 / 12 / 13}$ cell lines are shown alone for clarity. Data represent mean \pm s.e.m. of [biological replicates performed in triplicate $\left.(n=3-15)\right]$.

in this case, that is the receptors still remain accessible to $\beta$-arrestin because they are not being internalized. Cells treated with phenylarsine oxide might be compromised with respect to $G$ protein dissociation required for $\beta$-arrestin recruitment. In response to $\mathrm{PGF} 2 \alpha$, however, the pattern of inhibition was distinct, suggesting again that receptors were locked into a distinct trafficking itinerary, yielding two distinct fates for the same receptor complex activated by different ligands.

Similar asymmetric structural arrangements were also observed in other GPCR oligomers including the luteinizing hormone receptor (33), rhodopsin (34), mGluR2/3 heterodimers 


\section{A Ang II-Induced $\beta$ Arr1-Rlucll Recruitment B Ang II-Induced $\beta$ Arr2-Rlucll Recruitment}
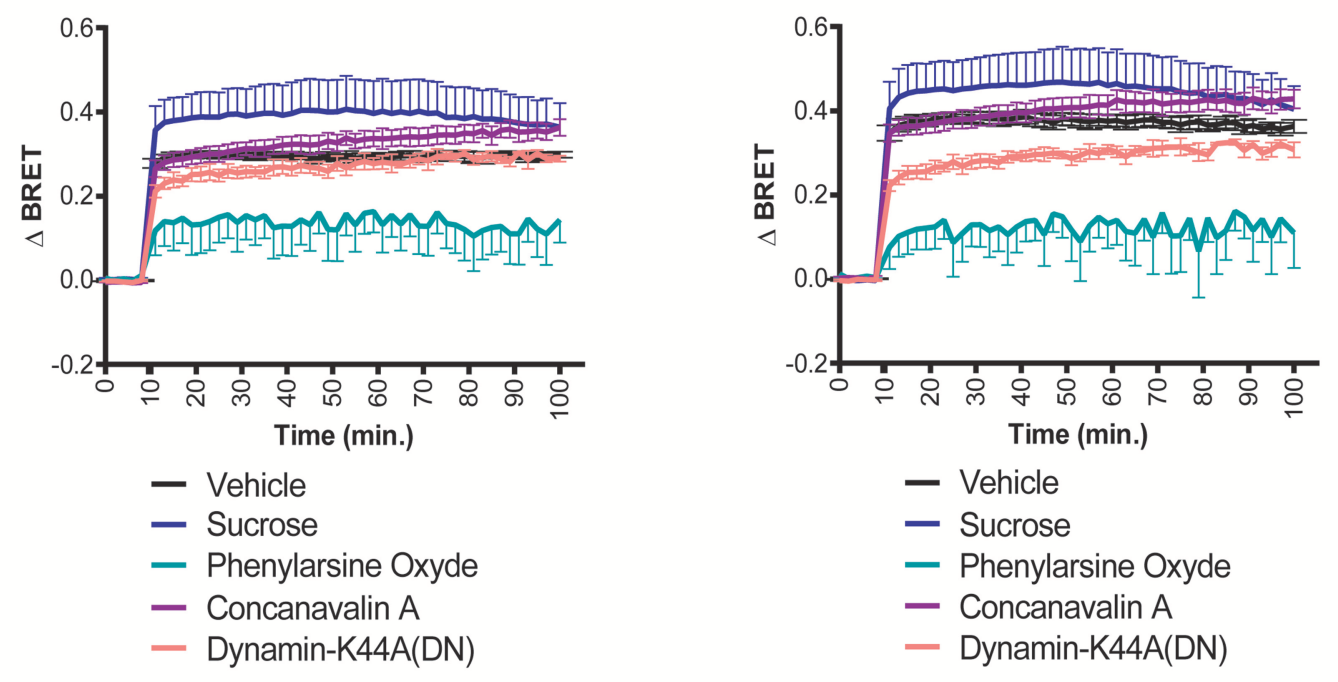

\section{PGF2 $\alpha$-Induced $\beta$ Arr1-Rlucll Recruitment D PGF2 $\alpha$-Induced $\beta$ Arr2-Rlucll Recruitment}
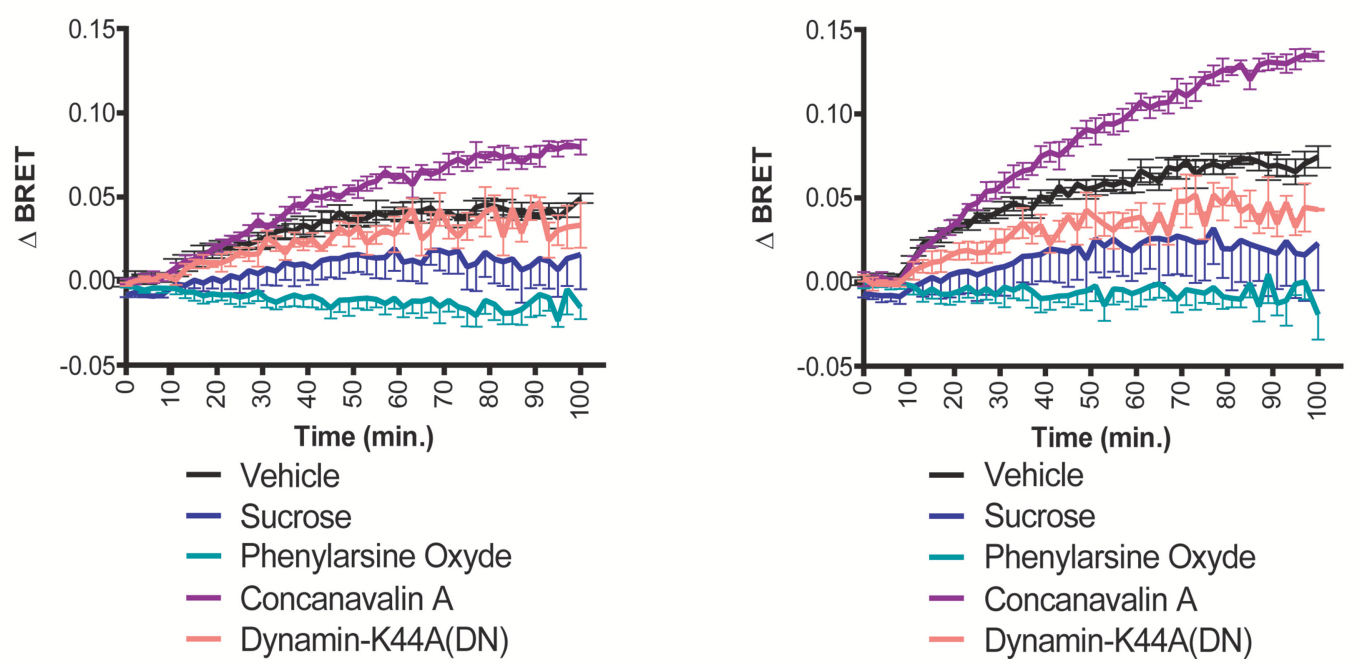

FIGURE 6 | Effects of endocytosis inhibitors on Ang II- and PGF2 $\alpha$-induced $\beta$-arrestin 1/2 recruitment to the AT1R/FP dimer. (A,B) Sucrose (blue lines, 450 mM) and phenylarsine oxide (blue-green lines, $2.5 \mu \mathrm{M}$ ) pretreatment (30 min) potentiated and diminished the recruitment of $\beta$-arrestin1/2-Rlucll to the AT1R-Venus/FP-WT dimer in response to Ang II (1 $\mu \mathrm{M})$, respectively. To a much lesser extent, concanavalin A (purple lines, $0.4 \mathrm{~g} / \mathrm{L}$ ) pretreatment (30 min) and the dominant negative mutant K44A dynamic (salmon lines; $0.5 \mu \mathrm{g}$ ) also potentiated and diminished the responses, respectively. (C,D) Concanavalin A (purple lines, $0.4 \mathrm{~g} / \mathrm{L}$ ) and phenylarsine oxide (blue-green lines, $2.5 \mu \mathrm{M}$ ) pretreatment (30 min) potentiated and diminished the recruitments of $\beta$-arrestin 1/2-Rlucll to the AT1R-Venus/FP-WT dimer in response to $\mathrm{PGF}_{2 \alpha}(1 \mu \mathrm{M})$, respectively. To a lower extent, sucrose (blue lines, $450 \mathrm{mM}$ ) and the dominant negative mutant K44A of dynamin (salmon lines; $\left.0.5 \mu \mathrm{g}\right)$ both diminished the responses. Data represent mean \pm s.e.m. of independent experiments performed in triplicate $(n=3-4)$.

(1), and leukotriene B4 receptor dimers (35). These studies indicate that individual protomers in GPCR dimers and oligomers could interact with shared $G$ proteins via distinct interfaces [see also (6)], providing a mechanism by which such structural asymmetries could lead to asymmetries in receptor conformation and functional outcomes. Such asymmetric conformational crosstalk may provide novel ways to imagine targeting heterodimers, which has been ignored in current drug discovery programs.
Other studies showed that AT1R may be an example of a dimer hub (36) with many different partners such as CB1 cannabinoid receptors (37) apelin receptors, $\alpha_{2} \mathrm{AR}$, and $\beta_{2} \mathrm{AR}$ receptor heterodimers (38-42). A more complete exploration of signaling and conformational profiles in GPCR heterodimers would get at the full scope of the impact of receptor protomers on one another.

The AT1R is an important target for treatment of hypertension and heart failure and angiotensin receptor blockers remain 
widely prescribed (43). A role for FP in the regulation of blood pressure has also been suggested (44). FP has been implicated in parturition with enhanced PGF $2 \alpha$ signaling initiating labor through the stimulation of myometrial contraction $(45,46)$. The AT1R is co-expressed in the myometrium and increased levels have been detected during pregnancy (47-49). Further study of this putative receptor heterodimer could yield novel drug targets for a number of diseases.

\section{DATA AVAILABILITY}

All datasets generated for this study are included in the manuscript and/or the supplementary files.

\section{REFERENCES}

1. Levitz J, Habrian C, Bharill S, Fu Z, Vafabakhsh R, Isacoff EY. Mechanism of assembly and cooperativity of homomeric and heteromeric metabotropic glutamate receptors. Neuron. (2016) 92:143-59. doi: 10.1016/j.neuron.2016.08.036

2. Wu H, Wang C, Gregory KJ, Han GW, Cho HP, Xia Y, et al. Structure of a class C GPCR metabotropic glutamate receptor 1 bound to an allosteric modulator. Science. (2014) 344:58-64. doi: 10.1126/science.1249489

3. Franco R, Martinez-Pinilla E, Lanciego JL, Navarro G. Basic pharmacological and structural evidence for class A G-proteincoupled receptor heteromerization. Front Pharmacol. (2016) 7:76. doi: 10.3389/fphar.2016.00076

4. Ferre S, Casado V, Devi LA, Filizola M, Jockers R, Lohse MJ, et al. G proteincoupled receptor oligomerization revisited: functional and pharmacological perspectives. Pharmacol Rev. (2014) 66:413-34. doi: 10.1124/pr.113.008052

5. Casado V, Cortes A, Mallol J, Perez-Capote K, Ferre S, Lluis C, et al. GPCR homomers and heteromers: a better choice as targets for drug development than GPCR monomers? Pharmacol Ther. (2009) 124:248-57. doi: 10.1016/j.pharmthera.2009.07.005

6. Han Y, Moreira IS, Urizar E, Weinstein H, Javitch JA. Allosteric communication between protomers of dopamine class A GPCR dimers modulates activation. Nat Chem Biol. (2009) 5:688-95. doi: 10.1038/nchembio.199

7. Smith NJ, Milligan G. Allostery at G protein-coupled receptor homo- and heteromers: uncharted pharmacological landscapes. Pharmacol Rev. (2010) 62:701-25. doi: 10.1124/pr.110.002667

8. Thomsen AR, Plouffe B, Cahill TJ III, Shukla AK, Tarrasch JT, Dosey AM, et al. (2016). GPCR-G protein-beta-arrestin super-complex mediates sustained G protein signaling. Cell. 166:907-19. doi: 10.1016/j.cell.2016.07.004

9. Shukla AK, Westfield GH, Xiao K, Reis RI, Huang LY, Tripathi-Shukla P, et al. Visualization of arrestin recruitment by a G-protein-coupled receptor. Nature. (2014) 512:218-22. doi: 10.1038/nature13430

10. Kang Y, Zhou XE, Gao X, He Y, Liu W, Ishchenko A, et al. Crystal structure of rhodopsin bound to arrestin by femtosecond X-ray laser. Nature. (2015) 523:561-7. doi: 10.1038/nature14656

11. Rasmussen SG, DeVree BT, Zou Y, Kruse AC, Chung KY, Kobilka TS, et al. Crystal structure of the beta2 adrenergic receptor-Gs protein complex. Nature. (2011) 477:549-55. doi: 10.1038/nature10361

12. Goupil E, Fillion D, Clement S, Luo X, Devost D, Sleno R, et al. Angiotensin II type I and prostaglandin F2alpha receptors cooperatively modulate signaling in vascular smooth muscle cells. J Biol Chem. (2015) 290:3137-48. doi: $10.1074 /$ jbc.M114.631119

13. Sleno R, Devost D, Petrin D, Zhang A, Bourque K, Shinjo $\mathrm{Y}$, et al. Conformational biosensors reveal allosteric interactions between heterodimeric AT1 angiotensin and prostaglandin F2alpha receptors. $J$ Biol Chem. (2017) 292:12139-52. doi: 10.1074/jbc.M117.793877

14. Devost D, Sleno R, Petrin D, Zhang A, Shinjo Y, Okde R, et al. Conformational profiling of the AT1 angiotensin ii receptor reflects biased agonism, G

\section{AUTHOR CONTRIBUTIONS}

DF and TH designed the study. DF, DD, and RS performed the experiments, analyzed the data, and generated the figures. $\mathrm{TH}$, DF, DD, and AI wrote and edited the paper.

\section{ACKNOWLEDGMENTS}

This work was supported by grants from the Canadian Institutes for Health Research (CIHR) to TH. DF was supported by a Ferring Fellowship in Reproductive Health. RS was supported by scholarships from the McGill CIHR Drug Development Training Program. We also thank Dr. Nicolas Audet (McGill University, Montréal) for useful discussions regarding statistical analysis.

protein coupling, and cellular context. J Biol Chem. (2017) 292:5443-56. doi: 10.1074/jbc.M116.763854

15. Schrage R, Schmitz AL, Gaffal E, Annala S, Kehraus S, Wenzel D, et al. The experimental power of FR900359 to study Gq-regulated biological processes. Nat Commun. (2015) 6:10156. doi: 10.1038/ncomms 10156

16. Ran FA, Hsu PD, Wright J, Agarwala V, Scott DA, Zhang F. Genome engineering using the CRISPR-Cas9 system. Nat Protoc. (2013) 8:2281-308. doi: $10.1038 /$ nprot.2013.143

17. Namkung Y, Le Gouill C, Lukashova V, Kobayashi H, Hogue M, Khoury E, et al. Monitoring $\mathrm{G}$ protein-coupled receptor and beta-arrestin trafficking in live cells using enhanced bystander BRET. Nat Commun. (2016) 7:12178. doi: $10.1038 /$ ncomms 12178

18. Sleno R, Petrin D, Devost D, Goupil E, Zhang A, Hebert TE. Designing BRETbased conformational biosensors for G protein-coupled receptors. Methods. (2016) 92:11-8. doi: 10.1016/j.ymeth.2015.05.003

19. Quoyer J, Janz JM, Luo J, Ren Y, Armando S, Lukashova V, et al. Pepducin targeting the $\mathrm{C}-\mathrm{X}-\mathrm{C}$ chemokine receptor type 4 acts as a biased agonist favoring activation of the inhibitory G protein. Proc Natl Acad Sci USA. (2013) 110:E5088-5097. doi: 10.1073/pnas.1312515110

20. Zimmerman B, Beautrait A, Aguila B, Charles R, Escher E, Claing A, et al. Differential beta-arrestin-dependent conformational signaling and cellular responses revealed by angiotensin analogs. Sci Signal. (2012) 5:ra33. doi: 10.1126/scisignal.2002522

21. Wrzal PK, Goupil E, Laporte SA, Hebert TE, Zingg HH. Functional interactions between the oxytocin receptor and the beta2-adrenergic receptor: implications for ERK1/2 activation in human myometrial cells. Cell Signal. (2012) 24:333-41. doi: 10.1016/j.cellsig.2011.09.019

22. Petrin D, Robitaille M, Hebert TE. Real-time BRET assays to measure G protein/effector interactions. Methods Mol Biol. (2011) 756:245-61. doi: 10.1007/978-1-61779-160-4_13

23. Bourque K, Petrin D, Sleno R, Devost D, Zhang A, Hebert TE. Distinct conformational dynamics of three $G$ protein-coupled receptors measured using FlAsH-BRET biosensors. Front Endocrinol. (2017) 8:61. doi: 10.3389/fendo.2017.00061

24. Leonard AP, Appleton KM, Luttrell LM, Peterson YK. A high-content, livecell, and real-time approach to the quantitation of ligand-induced betaArrestin2 and Class A/Class B GPCR mobilization. Microsc Microanal. (2013) 19:150-70. doi: 10.1017/S1431927612014067

25. Goupil E, Wisehart V, Khoury E, Zimmerman B, Jaffal S, Hebert TE, et al. Biasing the prostaglandin F2alpha receptor responses toward EGFRdependent transactivation of MAPK. Mol Endocrinol. (2012) 26:1189-202. doi: 10.1210/me.2011-1245

26. Paradis JS, Ly S, Blondel-Tepaz E, Galan JA, Beautrait A, Scott MG, et al. Receptor sequestration in response to beta-arrestin-2 phosphorylation by ERK1/2 governs steady-state levels of GPCR cell-surface expression. Proc Natl Acad Sci USA. (2015) 112:E5160-5168. doi: 10.1073/pnas.15088 36112

27. Woodward DF, Jones RL, Narumiya S. International union of basic and clinical pharmacology. LXXXIII: classification of prostanoid receptors, 
updating 15 years of progress. Pharmacol Rev. (2011) 63:471-538. doi: 10.1124/pr.110.003517

28. Griffin BW, Klimko P, Crider JY, Sharif NA. (1999). AL-8810: a novel prostaglandin F2 alpha analog with selective antagonist effects at the prostaglandin F2 alpha (FP) receptor. J Pharmacol Exp Ther. 290:1278-84.

29. Gurevich VV, Gurevich EV. Arrestins: critical players in trafficking of many GPCRs. Prog Mol Biol Transl Sci. (2015) 132:1-14. doi: 10.1016/bs.pmbts.2015.02.010

30. Mores KL, Cassell RJ, van Rijn RM. Arrestin recruitment and signaling by G protein-coupled receptor heteromers. Neuropharmacology. (2018). doi: 10.1016/j.neuropharm.2018.11.010

31. Luttrell LM, Wang J, Plouffe B, Smith JS, Yamani L, Kaur S, et al. Manifold roles of beta-arrestins in GPCR signaling elucidated with siRNA and CRISPR/Cas9. Sci Signal. (2018) 11:eaat7650. doi: 10.1126/scisignal.aat7650

32. Gibson AE, Noel RJ, Herlihy JT, Ward WF. Phenylarsine oxide inhibition of endocytosis: effects on asialofetuin internalization. Am J Physiol. (1989) 257:C182-184. doi: 10.1152/ajpcell.1989.257.2.C182

33. Jonas KC, Fanelli F, Huhtaniemi IT, Hanyaloglu AC. Single molecule analysis of functionally asymmetric G protein-coupled receptor (GPCR) oligomers reveals diverse spatial and structural assemblies. J Biol Chem. (2015) 290:387592. doi: $10.1074 /$ jbc.M114.622498

34. Mishra AK, Gragg M, Stoneman MR, Biener G, Oliver JA, Miszta P, et al. Quaternary structures of opsin in live cells revealed by FRET spectrometry. Biochem J. (2016) 473:3819-36. doi: 10.1042/BCJ20160422

35. Damian M, Martin A, Mesnier D, Pin JP, Baneres JL. Asymmetric conformational changes in a GPCR dimer controlled by G proteins. $E M B O$ J. (2006) 25:5693-702. doi: 10.1038/sj.emboj.7601449

36. Takezako T, Unal H, Karnik SS, Node K. Current topics in angiotensin II type 1 receptor research: focus on inverse agonism, receptor dimerization and biased agonism. Pharmacol Res. (2017) 123:40-50. doi: 10.1016/j.phrs.2017.06.013

37. Dai S, Hall DD, Hell JW. Supramolecular assemblies and localized regulation of voltage-gated ion channels. Physiol Rev. (2009) 89:411-52. doi: 10.1152 /physrev.00029.2007

38. Siddiquee K, Hampton J, McAnally D, May L, Smith L. The apelin receptor inhibits the angiotensin II type 1 receptor via allosteric trans-inhibition. $\mathrm{Br} \mathrm{J}$ Pharmacol. (2013) 168:1104-17. doi: 10.1111/j.1476-5381.2012.02192.x

39. Bellot M, Galandrin S, Boularan C, Matthies HJ, Despas F, Denis C, et al. Dual agonist occupancy of AT1-R- $\alpha 2 \mathrm{C}-\mathrm{AR}$ heterodimers results in atypical GsPKA signaling. Nat Chem Biol. (2015) 11:271-9. doi: 10.1038/nchembio.1766

40. Haspula D, Clark MA. MAPK activation patterns of AT1R and CB1R in SHR versus Wistar astrocytes: evidence of CB1R hypofunction and crosstalk between AT1R and CB1R. Cell Signal. (2017) 40:81-90. doi: 10.1016/j.cellsig.2017.09.002
41. Barki-Harrington L, Luttrell LM, Rockman HA. Dual inhibition of $\beta$ adrenergic and angiotensin II receptors by a single antagonist: a functional role for receptor-receptor interaction in vivo. Circulation. (2003) 108:1611-8. doi: 10.1161/01.CIR.0000092166.30360.78

42. Toth AD, Gyombolai P, Szalai B, Varnai P, Turu G, Hunyady L. Angiotensin type 1A receptor regulates $\beta$-arrestin binding of the $\beta 2$ adrenergic receptor via heterodimerization. Mol Cell Endocrinol. (2017) 442:113-24. doi: 10.1016/j.mce.2016.11.027

43. Borghi C, Rossi F. Role of the renin-angiotensin-aldosterone system and its pharmacological inhibitors in cardiovascular diseases: complex and critical issues. High Blood Press Cardiovasc Prev. (2015) 22:429-44. doi: 10.1007/s40292-015-0120-5

44. Yu Y, Lucitt MB, Stubbe J, Cheng Y, Friis UG, Hansen PB, et al. Prostaglandin F2 $\alpha$ elevates blood pressure and promotes atherosclerosis. Proc Natl Acad Sci USA. (2009) 106:7985-90. doi: 10.1073/pnas.0811834106

45. Jenkin G. Oxytocin and prostaglandin interactions in pregnancy and at parturition. J Rep Fertil Suppl. (1992) 45:97-111.

46. Mejia R, Waite C, Ascoli M. Activation of Gq/11 in the mouse corpus luteum is required for parturition. Mol Endocrinol. (2015) 29:238-46. doi: 10.1210/me.2014-1324

47. Yamaleyeva LM, Neves LA, Coveleskie K, Diz DI, Gallagher PE, Brosnihan KB. AT1, AT2, and AT(1-7) receptor expression in the uteroplacental unit of normotensive and hypertensive rats during early and late pregnancy. Placenta. (2013) 34:497-502. doi: 10.1016/j.placenta.2013.03.008

48. Cox BE, Ipson MA, Shaul PW, Kamm KE, Rosenfeld CR. Myometrial angiotensin II receptor subtypes change during ovine pregnancy. J Clin Invest. (1993) 92:2240-8. doi: 10.1172/JCI116827

49. Bird IM, Zheng J, Cale JM, Magness RR. Pregnancy induces an increase in angiotensin II type-1 receptor expression in uterine but not systemic artery endothelium. Endocrinology. (1997) 138:490-8. doi: 10.1210/endo.138.1.4879

Conflict of Interest Statement: The authors declare that the research was conducted in the absence of any commercial or financial relationships that could be construed as a potential conflict of interest.

Copyright @ 2019 Fillion, Devost, Sleno, Inoue and Hébert. This is an open-access article distributed under the terms of the Creative Commons Attribution License (CC $B Y)$. The use, distribution or reproduction in other forums is permitted, provided the original author(s) and the copyright owner(s) are credited and that the original publication in this journal is cited, in accordance with accepted academic practice. No use, distribution or reproduction is permitted which does not comply with these terms. 